\title{
Uptake of e-cigarettes among a nationally representative cohort of UK children
}

\author{
Anthony A. Laverty' , Eszter P. Vamos' ${ }^{2}$ Filippos Filippidis²
}

\begin{abstract}
INTRODUCTION Using nationally representative data this study examined experimentation with and regular use of e-cigarettes among children not using tobacco at age 11 years, followed up to age 14 years.

METHOdS Data come from 10982 children in the UK Millennium Cohort Study. Logistic regression assessed experimentation with and current use of e-cigarettes by age 14 years. We considered associations of sociodemographics at age 11 years with subsequent e-cigarette use, including data on family income, peer and caregiver smoking. Subsequent models were adjusted for current tobacco use to assess both the strength of the assocations between e-cigarette use and tobacco, and whether sociodemographics were associated with e-cigarettes independently of tobacco.

RESULTS Among 10982 children who reported never smoking at age 11 years, 13.9\% (1525) had ever tried an e-cigarette by age 14 years, and of these $18.2 \%$ (278) reported being current users. Children in lower income households were more likely to have tried an e-cigarette than those in higher income households (Adjusted Odds Ratio, AOR 1.89, $\mathrm{p}=0.002)$. Children who reported friend (AOR 2.28, $\mathrm{p}<0.001)$ or caregiver smoking (AOR 1.77, $\mathrm{p}<0.001$ ) at age 11 years were more likely to have tried an e-cigarette by age 14 years. After adjusting for current tobacco use, there was some attenuation of these associations, although associations of friend and caregiver smoking with e-cigarette use remained statistically significant.

CONCLUSIONS Children from lower income families were more likely to experiment with e-cigarettes by age 14 years, although this was heavily mediated by concurrent tobacco use. Caregiver and friend smoking are linked to trying e-cigarettes, although these relationships are less clear for regular e-cigarette use.
\end{abstract}

AFFILIATION

1 Public Health Policy Evaluation Unit, School of Public Health, Imperial College London, London, United Kingdom

2 Imperial College London, London, United Kingdom

CORRESPONDENCE TO Anthony A. Laverty. Public Health Policy Evaluation Unit, School of Public Health, Imperial College London, London, United Kingdom. E-mail: a.laverty@imperial. ac.uk

\section{KEYWORDS}

cigarette smoking, alternative tobacco products, youth smoking, new tobacco products

Received: 4 January 2018 Revised: 23 March 2018 Accepted: 3 April 2018

\section{INTRODUCTION}

Adolescents constitute a key population in the heated debate about electronic cigarettes (e-cigarettes). E-cigarettes are more popular among younger individuals, who are also more likely to believe that they are less harmful than cigarettes in the United Kingdom, but the patterns and pathways of use among adolescents remain unclear ${ }^{1-3}$. A key question in the debate is whether experimentation and use among adolescents is a gateway to smoking tobacco ${ }^{4,5}$. While multiple studies have shown that regular use of e-cigarettes and, to some extent, experimentation with the product are rare among non-smokers, the cross-sectional nature of these studies precludes conclusions with regards to transition from e-cigarettes to combustible tobacco and vice versa ${ }^{1,6}$.

Recently, longitudinal studies among adolescents in Europe and the United States have shown that students who try e-cigarettes are subsequently more likely to smoke cigarettes ${ }^{7-11}$. This association could indicate that the use of e-cigarettes is causally linked to smoking or simply reflects personal and psychosocial factors that are associated with adolescents' propensity to use nicotine and/or 
tobacco products in general. Little attention has been given to the factors that are associated with the initiation of e-cigarette use among adolescents, which could help to disentangle the complex relationship between e-cigarette and cigarette use during adolescence.

The aim of this study was to explore social and demographic factors associated with experimentation and current e-cigarette use in a longitudinal and nationally representative sample of adolescents in the United Kingdom.

\section{METHODS}

\section{Data source}

Data come from the UK Millennium Cohort Study (MCS), which is a longitudinal national birth cohort study of children born in the UK from September 2000 to January $2002^{12}$. The study uses a stratified cluster sampling design and over-sampling of smaller population groups including children in more disadvantaged areas.

This study uses data from the most recently available waves of the MCS (waves 5 and 6), conducted in 2011 and 2015, respectively, when children were aged approximately 11 and 14 years. Both waves involve administration of questionnaires to both children and their caregivers. The full sample size was 13287 at age 11 years and 11726 at age 14 years. We restricted the sample to children who reported never having tried smoking tobacco at age 11 years and were followed up at age 14 years, and had a sample of 10982 of which 9961 had complete data and were included in our regression analysis.

\section{Variables}

E-cigarette use was assessed in the wave 6 survey by asking children to denote which best describes them: 'I've never used or tried electronic cigarettes (e-cigarettes)'; 'I have used e-cigarettes but don't at all now'; 'I now smoke e-cigarettes occasionally but not every day'; 'I smoke e-cigarettes every day'. All but the first answer were considered ever use of e-cigarettes, while the last two answers were categorised as current use of e-cigarettes.

Tobacco use at age 14 years was categorised as never, former or irregular (having tried smoking once, being a previous smoker, or smoking less than one cigarette a week) and regular (at least weekly smoking tobacco). Friend smoking at age 11 years was assessed using the question: 'How many of your friends smoke cigarettes?' with answers ranging from 'none of them' to 'all of them', categorised as a binary variable.

Our models included data on age at follow-up (13 vs 14/15 years), gender (boys vs girls), country (England, Scotland, Wales, Northern Ireland), equivalised family income in five groups ${ }^{13}$, friend smoking (yes vs no) and caregiver current smoking (yes vs no, reported by the caregiver ).

\section{Analyses}

Associations between ever use of e-cigarettes by age 14 years with sociodemographics and exposure to caregiver or friend smoking at age 11 years were examined using logistic regression. These models were additionally adjusted for tobacco use at age 14 years. These same models were used to examine associations with current use of e-cigarettes at age 14 years among those who reported ever using e-cigarettes. We ran both sets of models initially without adjusting for tobacco use at age 14 years. Subsequent models were then adjusted for current tobacco use to assess both the strength of the relation between tobacco and e-cigarettes, and whether sociodemographics were associated with e-cigarette use independently of tobacco use.

Previous research has linked both tobacco and e-cigarette use to high levels of rebelliousness, low levels of parental support and a willingness to smoke $^{14}$. Here we also present sensitivity analyses among children considered at high risk of initiating smoking based on their parental support and antisocial behaviour (a binary variable for ever: being so noisy in public that people complained; stolen something from a shop; performed graffiti; damaged something in public on purpose). However, as we do not have data on pre-existing willingness to smoke, we did not use these data in our primary analyses.

All analyses and percentages reported were weighted using survey weights constructed by the MCS team to correct for differential non-response and to ensure national representativeness ${ }^{16}$.

\section{RESULTS}

Characteristics of the sample are shown in Supplementary table 1. 
Among 10982 children who reported never trying tobacco at age 11 years, $13.9 \%$ (1525) had ever tried an e-cigarette by age 14 years, and of these $18.2 \%$ (278) reported being current users of e-cigarettes. Details of the breakdown of e-cigarette use by tobacco use status are shown in Supplementary table 2 . Among those who had never tried cigarettes by age 14 years, e-cigarette ever use was $7.2 \%$, while among those who smoked cigarettes at least weekly, $84.3 \%$ had tried e-cigarettes.

In models not adjusted for current tobacco use (Table 1), children in lower income households were more likely to have tried an e-cigarette than those in higher income households (AOR 1.89, $\mathrm{p}=0.002$ ). Children who reported friend (AOR 2.28, $\mathrm{p}<0.001$ ) or caregiver smoking (AOR 1.77, $<<0.001)$ at age 11 years, were more likely to have tried an e-cigarette by age 14 years. After adjusting for current tobacco use there was some attenuation of these associations, although they were both still statistically significant (AOR 1.86, $\mathrm{p}=0.002$ for friend smoking; and AOR $1.36, \mathrm{p}=0.008$ for caregiver smoking). Differences across family income groups were not evident.

Only caregiver smoking was associated with an increased likelihood of being a current e-cigarette user (AOR 1.56, p=0.039). Family and friend smoking was not associated with being a current e-cigarette user in models adjusting for tobacco use status, while children in lower income households were less likely to be current users $(\mathrm{AOR}=0.43$, $\mathrm{p}=0.011$ ).

In analyses among children considered at risk of tobacco smoking based on their antisocial behaviours or lack of parental support, friend smoking was

Table 1: Associations of age 11 socio-demographics with e-cigarette use at age 14 among a cohort of UK children (2011-2014)

\begin{tabular}{|c|c|c|c|c|c|c|c|c|c|c|}
\hline & & Ever $t$ & ied c ciga & ttes & & Curre & c cigar & the use ar & ng ever & users \\
\hline & $\%$ & $\begin{array}{l}\text { Odds } \\
\text { Ratio }\end{array}$ & p value & $\begin{array}{l}\text { Odds } \\
\text { Ratio }\end{array}$ & p-value & $\%$ & $\begin{array}{l}\text { Odds } \\
\text { Ratio }\end{array}$ & p-value & $\begin{array}{l}\text { Odds } \\
\text { Ratio }\end{array}$ & p-value \\
\hline Age at follow- & & & & & & & & & & \\
\hline 13 years & 12.3 & ref & ref & ref & ref & 23.7 & ref & ref & ref & ref \\
\hline $14 / 15$ years & 17.0 & 1.32 & 0.002 & 1.21 & 0.080 & 17.8 & 0.68 & 0.081 & 0.63 & 0.030 \\
\hline Gender & & & & & & & & & & \\
\hline Boys & 16.4 & ref & ref & ref & ref & 19.0 & ref & ref & ref & ref \\
\hline Girls & 15.3 & 0.91 & 0.309 & 0.66 & $<0.001$ & 18.7 & 1.08 & 0.656 & 0.89 & 0.524 \\
\hline Country & & & & & & & & & & \\
\hline England & 15.6 & ref & ref & ref & ref & 19.7 & ref & ref & ref & ref \\
\hline Wales & 16.2 & 0.98 & 0.885 & 0.97 & 0.831 & 18.3 & 1.02 & 0.959 & 1.03 & 0.933 \\
\hline Scotland & 19.1 & 1.25 & 0.464 & 0.83 & 0.324 & 14.5 & 0.69 & 0.338 & 0.47 & 0.113 \\
\hline N. Ireland & 13.7 & 0.77 & 0.098 & 0.86 & 0.342 & 15.3 & 0.76 & 0.462 & 0.95 & 0.883 \\
\hline Income & & & & & & & & & & \\
\hline Highest & 11.3 & ref & ref & ref & ref & 22.4 & ref & ref & ref & ref \\
\hline Second & 12.1 & 0.95 & 0.669 & 0.96 & 0.748 & 18.0 & 0.72 & 0.282 & 0.67 & 0.216 \\
\hline Middle & 16.0 & 1.32 & 0.010 & 1.32 & 0.020 & 18.6 & 0.76 & 0.319 & 0.73 & 0.268 \\
\hline Fourth & 15.7 & 1.09 & 0.535 & 0.90 & 0.415 & 19.5 & 0.82 & 0.497 & 0.64 & 0.152 \\
\hline Lowest & 22.4 & 1.89 & 0.002 & 1.34 & 0.092 & 17.6 & 0.64 & 0.142 & 0.43 & 0.011 \\
\hline Friend smoking & & & & & & & & & & \\
\hline No & 15.0 & ref & ref & ref & ref & 19.3 & ref & ref & ref & ref \\
\hline Yes & 31.2 & 2.28 & $<0.001$ & 1.86 & 0.002 & 17.0 & 0.79 & 0.442 & 0.67 & 0.168 \\
\hline Caregiver smok & & & & & & & & & & \\
\hline No & 13.2 & ref & ref & ref & ref & 17.3 & ref & ref & ref & ref \\
\hline Yes & 23.8 & 1.77 & $<0.001$ & 1.36 & 0.008 & 21.9 & 1.56 & 0.039 & 1.31 & 0.229 \\
\hline Tobacco use at & & & & & & & & & & \\
\hline Never & 8.1 & - & - & ref & ref & 9.7 & - & - & ref & ref \\
\hline At least ever & 57.4 & - & - & 15.50 & $<0.001$ & 22.6 & - & - & 2.88 & $<0.001$ \\
\hline At least weekly & 84.0 & - & - & 57.75 & $<0.001$ & 38.1 & - & - & 8.50 & $<0.001$ \\
\hline
\end{tabular}


associated with being an ever e-cigarette user, while there were no associations between household income and ever or current e-cigarette use (Supplementary table 3).

\section{DISCUSSION}

Using nationally representative longitudinal data from the UK we found that children from lower income families were more likely to try e-cigarettes but that this association was heavily mediated by their tobacco use. We also found that $7.2 \%$ of 14 -year olds that had never tried cigarettes had experimented with e-cigarettes. Further research into the characteristics of this group and their potential trajectories towards tobacco use is warranted.

Having friends and caregivers who smoke has been identified as an important predictor of smoking tobacco in young age in other work and our analysis suggests that similar influences are important in the use of e-cigarettes ${ }^{17}$. E-cigarette use is much more frequent among adult smokers compared with non-smokers ${ }^{1}$; therefore, this finding could reflect exposure to e-cigarettes in the proximate social environment, which has been associated with adolescent e-cigarette use ${ }^{18}$. Nonetheless, whether there is an independent association between caregiver or peer smoking and the likelihood of trying e-cigarettes remains an open question ${ }^{19}$. We also conducted analyses focused on the subset of children considered at high-risk of smoking due to their antisocial behaviours or lack of parental support following on from research that has attempted to disentangle these effects ${ }^{14}$. These analyses found that friend smoking, but not caregiver smoking, was associated with trying e-cigarettes and that the differences across income groups may be explained by these factors.

The main strengths of this study are the nationally representative sample and the longitudinal design, which allowed us to identify the potential association of certain sociodemographic factors with e-cigarette use within a period of three years. Importantly, this was the period between ages 11 and 14 years, which is a time when many adolescents start experimenting with tobacco and nicotine products ${ }^{20}$. However, the UK Millennium Cohort Study did not assess use of e-cigarettes at age 11 years, hence we could not reliably identify new e-cigarette users between ages
11 and 14 years. The prevalence of e-cigarette use at the time wave 5 was conducted was relatively low in the UK and we excluded those who had already tried cigarettes from the analysis ${ }^{1,21}$. As the majority of young people will not try tobacco products until later in adolescence ${ }^{20}$, we expect that only a very small number of individuals included in our study had already tried e-cigarettes by age 11 years. It should be noted that use of e-cigarettes was additionally assessed using a single question that did not include details on whether the e-cigarettes used contained nicotine or the intensity of use. While adolescence is an important period for experimentation with e-cigarettes and other products, further work should also focus on long-term changes.

\section{CONCLUSIONS}

In nationally representative data from the United Kingdom, $13.9 \%$ had tried e-cigarettes by the age of 14 years, and of these $18.0 \%$ reported being current users of e-cigarettes. Those from lower income families were more likely to experiment with e-cigarettes by age 14 years, although this is heavily mediated by their tobacco use. Similar to tobacco smoking, caregiver and friend smoking are linked to trying e-cigarettes, although these relationships are less clear for regular use of e-cigarettes.

\section{REFERENCES}

1. Filippidis FT, Laverty AA, Gerovasili V, et al. Two-year trends and predictors of e-cigarette use in 27 European Union member states. Tob Control 2017;26:98-104. doi:10.1136/tobaccocontrol-2015-052771

2. Hilton $\mathrm{S}$, Weishaar $\mathrm{H}$, Sweeting $\mathrm{H}$, et al. E-cigarettes, a safer alternative for teenagers? A UK focus group study of teenagers' views. BMJ Open 2016;6:e013271. doi:10.1136/bmjopen-2016-013271

3. Yong H-H, Borland R, Balmford J, et al. Prevalence and correlates of the belief that electronic cigarettes are a lot less harmful than conventional cigarettes under the different regulatory environments of Australia and the UK. Nicotine Tob Res 2016;:1-7. doi:10.1093/ntr/ntw137

4. Schneider S, Diehl K. Vaping as a Catalyst for Smoking? An Initial Model on the Initiation of Electronic Cigarette Use and the Transition to Tobacco Smoking Among Adolescents. Nicotine Tob Res 2015;:ntv193. doi:10.1093/ntr/ntv193

5. Chatterjee K, Alzghoul B, Innabi A, et al. Is vaping a gateway to smoking: a review of the longitudinal studies. Int J Adolesc Med Health 2016;:1-7. doi:10.1515/ijamh-2016-0033 
6. Bauld L, MacKintosh AM, Ford A, et al. E-Cigarette Uptake Amongst UK Youth: Experimentation, but Little or No Regular Use in Nonsmokers. Nicotine Tob Res 2015;18:102-3. doi:10.1093/ntr/ntv132

7. Primack BA, Soneji S, Stoolmiller M, et al. Progression to traditional cigarette smoking after electronic cigarette use among us adolescents and young adults. JAMA Pediatr 2015;:1-7. doi:10.1001/jamapediatrics.2015.1742

8. Wills TA, Knight R, Sargent JD, et al. Longitudinal study of e-cigarette use and onset of cigarette smoking among high school students in Hawaii. Tob Control 2017;26:349. doi:10.1136/tobaccocontrol-2015-052705

9. Leventhal AM, Strong DR, Kirkpatrick MG, et al. Association of electronic cigarette use with initiation of combustible tobacco product smoking in early adolescence. JAMA 2015;314:700-7. doi:10.1001/jama.2015.8950

10. Best C, Haseen F, Currie D, et al. Relationship between trying an electronic cigarette and subsequent cigarette experimentation in Scottish adolescents: a cohort study. Tob Control 2017;:tobaccocontrol-2017-053691. doi:10.1136/tobaccocontrol-2017-053691

11. Conner M, Grogan S, Simms-Ellis R, et al. Do electronic cigarettes increase cigarette smoking in UK adolescents? Evidence from a 12-month prospective study. Tob Control 2017;:tobaccocontrol-2016-053539. doi:10.1136/tobaccocontrol-2016-053539

12. Millennium Cohort Study, A Guide to the Datasets. http://www.cls.ioe.ac.uk/shared/get-file. ashx?id=1806\&itemtype $=$ document. Accessed January 2017.

13. Organisation for Economic Cooperation and Development (2011).Society at a glance: OECD social indicators. http://www.oecd.org/berlin/47570121.pdf. Accessed January 2017.

14. Wills TA, Sargent JD, Gibbons FX, et al. E-cigarette use is differentially related to smoking onset among lower risk adolescents. Tob Control 2016;:1-6. doi:10.1136/tobaccocontrol-2016-053116

15. Kelly Yvonne, Goisis Alice, Sacker Amanda, et al. What influences 11-year-olds to drink? Findings from the Millennium Cohort Study. BMC Public Health 2015;16:169. doi:10.1186/s12889-016-2847-x

16. Connelly R, Platt L. Cohort profile: UK Millennium Cohort Study (mcs). Int J Epidemiol 2014;43:1719-25. doi:10.1093/ije/dyu001

17. Filippidis FT, Agaku IT, Vardavas CI. The association between peer, parental influence and tobacco product features and earlier age of onset of regular smoking among adults in 27 European countries. Eur J Public Health 2015;25:814-8. doi:10.1093/eurpub/ckv068

18. Krishnan-Sarin S, Morean ME, Camenga DR, et al. E-cigarette use among high school and middle school adolescents in Connecticut. Nicotine Tob Res 2014;:130. doi:10.1093/ntr/ntu243
19. Pentz MA, Shin HS, Riggs N, et al. Parent, peer, and executive function relationships to early adolescent e-cigarette use: A substance use pathway? Addict Behav 2015;42:73-8. doi:10.1016/j.addbeh.2014.10.040

20. The NHS Information Centre for Health and Social Care. Smoking, drinking and drug use among young people in England in 2014. 2015.https://www.gov.uk/ government/statistics/smoking-drinking-and-druguse-among-young-people-in-england-2014. Accessed January 2017.

21. Yong HH, Borland R, Balmford J, et al. Trends in E-Cigarette awareness, trial, and use under the different regulatory environments of Australia and the United Kingdom. Nicotine Tob Res 2015;17:1203-11. doi:10.1093/ntr/ntu231
ACKNOWLEDGEMENTS The Public Health Policy Evaluation Unit at Imperial College is grateful for the support of the NIHR School of Public Health Research.

CONFLICTS OF INTEREST Authors have completed and submitted the ICMJE Form for Disclosure of Potential Conflicts of Interest and none was reported.

FUNDING

A.A Laverty is funded by the National Institute for Health Research (NIHR) (RP 014-04032).

PROVENANCE AND PEER REVIEW

Not commissioned; externally peer reviewed 